\title{
Poultry biodiversity for alternative farming systems development
}

\author{
Edoardo Fiorilla ${ }^{1}$, Alice Cartoni Mancinelli ${ }^{2}$, Marco Birolo $^{3}$, Cesare Castellini ${ }^{2}$, Dominga \\ Soglia ${ }^{1}$, Elisabetta Macchi $^{1}$, Silvia Mioletti ${ }^{1}$, Barbara Miniscalco ${ }^{1}$, Stefano Sartore ${ }^{1}$, \\ Riccardo Franco ${ }^{1}$, Stefano Nurisso ${ }^{1}$, Maristella Baruchello ${ }^{4}$, Martina Tarantola ${ }^{1}$, Paola \\ Sacchi $^{1}$, Achille Schiavone ${ }^{1}$, and Cecilia Mugnai ${ }^{{ }^{*}}$ \\ ${ }^{1}$ Department of Veterinary Sciences, University of Turin, Largo Braccini 2, 10095, Grugliasco, Turin, \\ Italy \\ ${ }^{2}$ Department of Agricultural, Environmental and Food Science, University of Perugia, Borgo XX \\ Giugno 74, 06124, Perugia, Italy \\ ${ }^{3}$ Department of Agronomy, Food, Natural resources, Animals and Environment, University of \\ Padova, Viale dell'università, 16, 35020, Legnaro, Padova, Italy \\ ${ }^{4}$ Veneto Agricoltura, Agenzia Veneta per l'innovazione nel Settore primario, Viale dell'Università 14, \\ 35020 Legnaro, Padova, Italy
}

\begin{abstract}
Poultry biodiversity represents a key factor to improve poultry resilience and promote sustainable and low input farming systems. The EU and member states promote protection of livestock biodiversity and the development of alternative farming through funding projects such as "Local Chicken Breeds in Alternative Production Chain: Welfare, Quality and Sustainability" (funded by the Italian Ministry of Research and University). The aim of the present research was to identify among five different poultry genotypes Bionda Piemontese (BP), Robusta Maculata (RM), RM x Sasso (RMxS), BP x Sasso (BPxS) and a commercial hybrid (Ross 308) the best suitable breed in terms of productivity and welfare for alternative housing system. A total of 300 (60 x genotype), 21 days old male birds were randomly allotted in two housing systems: 1) standard intensive farming (controlled environment, $33 \mathrm{~kg} / \mathrm{m}^{2}$ and standard diet) and 2) free-range ("natural" environmental conditions, $21 \mathrm{~kg} / \mathrm{m}^{2}$, access to outdoor area and low-input diet). Slaughtering was performed at 81 days of age. During the trial, the productive performance and behaviour of the animals were evaluated. The housing system, the genotype and their interaction significantly affected many of the studied variables, showing broiler not the ideal genotype for extensive farming system, which is more suited for low/medium performance strains.
\end{abstract}

\section{Introduction}

Humans are in continuous expansion, as FAO states, by 2050 global population will reach 10 billion people and, with this constant population increase, the consumption of food from

\footnotetext{
*Corresponding author: cecilia.mugnai@unito.it
} 
animal origin will increase dramatically. It will be necessary to increase the number of farmed animals and implement new ways of farming.

The sustainability of intensive farming system is considered low, and the situation will worsen every year. The main phenomena related to intensive farming are deforestation, greenhouse gasses emissions, excessive consumption and pollution of land and water [1]. Another side effect of this process is the reduction of genetic variability and the consequent vulnerability of animals to environmental stress [2].

Poultry farming has a better environmental impact than other animal production chains thanks to the high efficiency in converting feed into meat or egg. The shorter production cycle and the strong genetic selection carried out to increase production performance represent an advantage over ruminant or swine farming. This is particularly evident in the poultry meat production, in fact, modern broilers reach slaughtering weights in short cycles of about 40 days with a high percentage of meat yield [3]. Unfortunately, in addition to all the benefits listed above these high-performance strains (HPS) show welfare and health issues, skeletal imbalances, metabolic disorders, and muscle abnormalities, which affect the appearance of the meat, nutritional traits, and acceptance by consumers [4, 5].

These are some of the main reasons why new sustainable and alternative farming systems need to be identified. However, poultry meat and egg production rely on these HPSs presenting major animal health and welfare concerns [6]. As a result, there is a growing demand in developed countries for poultry meat and eggs from welfare-friendly farming systems [7]. Alternative poultry production is more expensive than intensive, but supports biodiversity, animal welfare, local economies and the multifunctionality of farms, providing eggs and meat to which a growing part of consumers attributes high ethical value, quality and taste [8].

Alternative systems (organic, biodynamics, free-range) require birds adapted to less controlled environment, high foraging aptitude, active immune response, and thermotolerance. The response of chickens to alternative systems and to different climatic conditions have not been sufficiently investigated and only few commercial breeds are available for these rearing systems, HPS, unlike Local Breeds (LBs), are highly unsuited to this purpose [9].

Nowadays, the preservation of poultry biodiversity is a key objective in all developed countries [10]. The possibility of improving LBs originates from the balance between the possible benefits (good health and welfare, resistance and resilience to heath stress, lower dietary requirements, reduced veterinary cares) and other unfavourable aspects (low performance, low meat yield) [11]. Accordingly, an essential step is the improvement of production efficiency in LBs. Crossbreeding is the main tool used in poultry, which normally involves a cross between HPS and LBs, with the aim of combining the production capacity of the former with the latter adaptability to natural environment. Cross breeding also maximizes the expression of heterosis and normally improves fitness characteristics [12].

Moreover, since the current HPS are specialized in either meat or egg production and egg production requires only females, the male of egg-type strain, due to their slow-growth rate, are killed at 1 day-old. Ethical reasons exist against this practice and the use of dual-purpose breeds could be a solution to this issue: the males and the females of local breeds could be farmed for meat and eggs, respectively. An additional reason to safeguard LBs derives from their ability to produce meat and eggs in alternative systems, with low-input diets and with outdoor run that produce meat and eggs with higher welfare standards [13]. These aspects meet the attitude of consumer in developed countries where people can make an opinionated decision about their meal taking in considerations animal welfare, sustainability, nutritional, sensory, and ethical factors. It is obvious that, in most countries where poverty and hunger is widespread, HPS still represents a good opportunity to provide quite cheap high value food $[14,15]$. Worldwide, conventional farming systems account for $67 \%$ of poultry meat 
production and $50 \%$ of eggs; an increase in local poultry farming is therefore feasible if supported by a productive and economic perspective [16]. The conservation of native breeds is also an important component of poultry biodiversity. The Food and Agriculture Organization of the United Nations (FAO) stated that $55 \%$ of all local poultry breeds are found in Europe and the Caucasus regions [16]. In Italy 22 breeds have been included in the Indigenous Poultry Register and most of them are included in the FAO Domestic Animal Diversity Information System (DAD-IS) database [17].

In European countries, the development of sustainable farming systems and the protection of biodiversity (animal and vegetal) are encouraged, especially in the more rural areas and the collaboration between associations, farmers, and scientific partners such as universities is incentivized. For this reason, the Italian Ministry of Research and University funded the project PRIN "USE OF LOCAL CHICKEN BREEDS IN ALTERNATIVE PRODUCTION CHAIN: WELFARE, QUALITY AND SUSTAINABILITY" with the aim to promote the use of local chicken breeds in alternative production chains through the development of crossbreeds to increase the production efficiency. This fact represents an opportunity to mobilize some resources on the breeding of local breeds and products that generate work and quality products obtained from animals that are present in the Italian territory [18]. In particular, in Italy there are some associations such as the Consortium for the Bionda Piemontese breed and Veneto Agriculture [19], partners of the above-mentioned project, that have been working for years for Italian poultry breeds conservation and to provide assistance and birds rural farmers.

The Bionda Piemontese (BP), is a native breed of the Piedmont region (north-west, Italy) is characterized by a blond plumage and a black tail. Currently they are bred mainly for meat production and are slaughtered at around 24 weeks of age, although they are considered dualpurpose breeds. In 2013, the population size was 16,000 birds. The annual laying production is concentrated in the spring-summer period and is around 180-200 units [20]. The breeders of BP and RM are included in the Consortium for the conservation of the breed and in the biodiversity conservation project of Italian poultry breeds and sponsored by the Ministry of Policies Agricultural, Food and Forestry (https://www.pollitaliani.it/en/). Knowledge of growth performance is therefore considered a requirement and a fundamental contribution to the improvement and conservation of local poultry breeds.

The Robusta Maculata (RM) is a native breed of the Veneto region (north-east, Italy) characterized by a silver-white plumage edged and irregularly spotted with black. It is a dualpurpose breed with a good aptitude for egg production and medium precocity. The Robusta Maculata is a rustic breed with good grazing aptitude and able to adapt to different agricultural environments. It adapts well to both extensive breeding and organic farming. Roosters reach a weight of 3.8-4.4 kg while females weigh an average of 2.8-3.3 kg. It is quite early and lays eggs with a pink to brown colour. Production is around 140-160 eggs per cycle with a weight of 55-60 g. The recommended slaughtering age is 18-22 weeks [21].

The sustainable use of genetic resources in extensive and organic systems is an alternative practice to conventional farming [22]. BP and RM perform well in these alternative systems and retain adaptation to low input farming systems that can positively affect welfare and quality; the products obtained are officially recognized as traditional and usually sold as whole carcasses and/or processed meat products $[23,24]$. These properties contribute to the value of this production and support the proposal of a retention situation for this breed.

In the present research, preliminary results of the growth performance and behavioural patterns of BP and RM chickens and their F1, crossed with a higher productivity breed (Sasso), were evaluated and compared with the Ross 308 chickens in two housing systems (conventional and free-range), to identify the breed better adapted for a particular system, offering the greatest benefits in terms of productivity and welfare. 


\section{Materials and methods}

\subsection{Birds and housing systems}

The present trial was performed in the poultry farm of the Department of Veterinary Sciences of University of Turin (Italy), from March to July 2021 and the experimental protocol was approved by the Bioethical Committee of the University of Turin (Italy) (Prot. ID: 251833). 300 chicks (60 x genotype) of five different poultry genotypes, Robusta Maculata (RM), Bionda Piemontese (BP), RM x Sasso (RMxS), BP x Sasso (BPxS) and commercial hybrid (Ross 308) were hatched by a local farmer [25]. Chicks were vaccinated against Marek and Newcastle diseases and sexing was done based on visual analysis of cloaca at hatching.

Chicks were reared for the first 20 days in the brood divided into five pens, one for each genotype. Each pen was $1 \mathrm{~m}$ wide and $2 \mathrm{~m}$ long and was covered with wood shavings $(20 \mathrm{~cm}$ deep) as litter equipped with a waterproof floor and walls, environmentally controlled with temperature and relative humidity $(\mathrm{RH})$ ranging from 32 to $20^{\circ} \mathrm{C}$ and from 70 to $65 \% \mathrm{RH}$, respectively.

At 21 days until slaughter, birds were randomly divided into two different rearing systems: conventional (33 $\mathrm{kg}$ of meat per $\left.\mathrm{m}^{2}\right)$ and free-range $\left(21 \mathrm{~kg}\right.$ of meat per $\left.\mathrm{m}^{2}\right)$. For each genotype and system, three replicates were made $(n=10$ cockerels $/ 5$ genotypes $/ 2$ housing systems/3 replicates).

In the conventional system, the lighting schedule was $16 \mathrm{~h}$ light, $8 \mathrm{~h}$ darkness for the whole trial. Environmental conditions in the poultry-house, temperature and relative humidity, were set according to the Ross guidelines [26]. Whereas for free-range system no lightning schedule was set, and birds were exposed to natural temperature and photoperiod. The animals were left free to stay either outside or inside at any time of the day, outdoor access was closed for the night (20.00-06.00) till May and then left open over $24 \mathrm{~h}$ till the end of experimentation.

The whole facility, including the outdoor areas, was protected from wild birds and predators with fences. The bird's health status and mortality and the environmental parameters were daily checked during the whole experimental period.

Slaughtering was performed in a commercial slaughterhouse at 81 days old, accordingly to EU recommendation for organic poultry production [27].

\subsection{Diets}

Three different feeds were used: a starter (administered from 0 to 21 days of age to all birds) and two grower/finisher diets (a standard and a low input diet). The standard diet was formulated to meet the recommended energy and protein levels for Ross and administered from 21 days of age until slaughter to the birds reared in the conventional system. The low input diet was formulated with the aim of achieving a reduced content $(-10 \%$ on average) of protein and energy. In the low input diet, the imported soybean meal was replaced by soybean meal and faba bean, GMOs free and from Italian cultivations. This diet was administered from 21 days of age until slaughter to the birds reared of free-range group. The ingredients and chemical composition of the experimental diets are reported in Table 1. The diets were analyzed to determine the contents of dry matter (934.01), ash (967.05), and crude protein (2001.11) by AOAC [29] methods. Ether extract was analyzed after acid hydrolysis [30] 
Table 1. Formulation (\%), chemical composition (\% as fed) and energetic value (MJ kg-1) of experimental diets

\begin{tabular}{|c|c|c|c|}
\hline Housing System & \multirow{2}{*}{ Starter } & \multirow{2}{*}{$\begin{array}{l}\text { Industrial } \\
\text { Standard }\end{array}$} & \multirow{2}{*}{$\begin{array}{l}\text { Free-range } \\
\text { Low input }\end{array}$} \\
\hline Diet & & & \\
\hline \multicolumn{4}{|c|}{ Ingredients } \\
\hline Corn & 55 & 57 & 58 \\
\hline Soybean oil & 2 & 3 & 2 \\
\hline Soybean meal* & - & - & 20 \\
\hline Soybean meal** & 25 & 15 & - \\
\hline Whole Soy & 14 & 21 & - \\
\hline Faba bean & - & - & 16 \\
\hline Calcium Carbonate & 1.8 & 1.8 & 1.8 \\
\hline Monocalcium phosphate & 1.3 & 1.3 & 1.3 \\
\hline Sodium chloride & 0.4 & 0.4 & 0.4 \\
\hline Vitamin-mineral premix & 0.5 & 0.5 & 0.5 \\
\hline \multicolumn{4}{|c|}{ Chemical composition } \\
\hline Dry matter & 88.53 & 87.48 & 87.37 \\
\hline Crude protein & 20.99 & 18.01 & 16.26 \\
\hline Ether extract & 6.48 & 8.49 & 4.74 \\
\hline Crude fibre & 3.17 & 1.72 & 2.68 \\
\hline Ash & 6.15 & 6.02 & 6.06 \\
\hline Lysine§ & 1.20 & 1.07 & 0.95 \\
\hline Met. + Cist. $\S$ & 0.71 & 0.66 & 0.53 \\
\hline Calcium $^{\S}$ & 1.01 & 1.00 & 0.99 \\
\hline Phosphorus§ & 0.70 & 0.68 & 0.68 \\
\hline $\mathrm{Ca} / \mathrm{P}^{\S}$ & 1.44 & 1.46 & 1.46 \\
\hline Metabolizable Energy & 3089 & 3252 & 2921 \\
\hline
\end{tabular}

*: National Soybean meal GMOs free, $44.0 \%$ CP. **: Imported Soybean meal GMOs, $49.0 \%$ CP. ${ }^{+}$Amounts per kg: Vit. A 12,500 IU; Vit. D3 5000 IU; Vit. B1 2.5 mg; Vit. B2 9 mg; Vit. B6 1.25 mg; Vit. B12 $0.01 \mathrm{mg}$; $\alpha$-tocopherol acetate $75 \mathrm{mg}$; Biotin $0.15 \mathrm{mg}$; Vit. K $4.0 \mathrm{mg}$; Niacin $60 \mathrm{mg}$; Folic acid $2.00 \mathrm{mg}$; Pantothenic acid $10 \mathrm{mg}$; Choline chloride $600 \mathrm{mg}$; Mn $100 \mathrm{mg}$; Fe $80 \mathrm{mg}$; Zn 80 mg; Cu 8.0 mg; I 2.0 mg; Se 0.2 mg. ${ }^{\S}$ Estimated values Feedipedia, [28].

\subsection{Productive performance}

The individual live weight (LW) and feed intake (FI; at a pen level) of the chickens were weekly recorded using an electronic scale (KERN PLE- N v. 2.2). Daily weigh gain and feed conversion ratio (FCR) were also calculated. To calculate mortality death birds were also daily recorded and causes of death evaluated by necropsy.

\subsection{Behavioural analysis}

During the week prior to slaughtering (from 73 to 80d), behavioural observations using a digital video camera (Sony 4K, FDR-AX43) were performed. The videos were analysed 
afterwards by two trained observers, using the continuous sampling method [31] for three minutes for each replication, during 2 periods (morning, starting at 09.00 am and afternoon, from $05.00 \mathrm{pm}$ ), of $1.5 \mathrm{~h}$ each.

The behavioural observations (Table 2) were divided into 6 macro-categories: feeding (scratching, feeding from feeders and drinkers, grass/object pecking); locomotor (walking, running, flapping wings while running); social (menacing each other without fighting, fighting, gentle pecking, allo-preening); resting (crouching, standing still); comfort (sand bath, self-preening); stretching (leg stretching, wing stretching).

The behaviour was recorded on a purpose-designed table (based on the major behaviours in the broiler ethogram chosen from preliminary observations), and their respective frequencies were calculated as a percentage of the total observed behaviours. As no significant differences were found between periods, all data were pooled.

Table 2. Designed table of macro-categories and corresponding behaviours used for behavioural analysis

\begin{tabular}{|l|l|}
\hline Macro-categories & Behaviour \\
\hline \multirow{4}{*}{ Feeding } & Scratching \\
\cline { 2 - 2 } & Feeding \\
\cline { 2 - 2 } & Grass/objects pecking \\
\hline \multirow{4}{*}{ Locomotor } & Walking \\
\cline { 2 - 2 } & Running \\
\cline { 2 - 2 } & Wing flap running \\
\hline \multirow{4}{*}{ Rocial } & Menacing \\
\cline { 2 - 2 } & Fighting \\
\cline { 2 - 2 } & $\begin{array}{l}\text { Gentle Pecking } \\
\text { Allo-Preening }\end{array}$ \\
\hline \multirow{2}{*}{ Comfort } & Crouching \\
\cline { 2 - 2 } & Standing \\
\hline \multirow{2}{*}{ Stretching } & Sand bath \\
\cline { 2 - 2 } & Self-Preening \\
\hline
\end{tabular}

\subsection{Statistical analysis}

A linear model [32] was used to evaluate the effect of genotype and housing system. For the final live weight, the repeated effect of chicks was included as random in the model. The Gompertz coefficients have been evaluated for the different genetic groups with a non-linear model (proc NL) using the following equation:

$$
L W_{t}=b 1 * \exp \{-\exp [-b 3 *(\text { time in wk }-b 2)]\},
$$

$L W_{t}$ was the live weight of any chicken at a given wk,

$b 1=$ adult weight (asymptote),

$b 2=$ the slope at flex point

$b 3=$ the point of flex. 
Goodness of fit of the model to the data was determined on each breed and housing system separately using adjusted coefficient of determination $\left(\mathrm{R}^{2}\right)$.

Difference between groups were assessed by ANOVA test with a Bonferroni multiple ttest. Differences with at least a $P \leq 0.05$ value were considered statistically significant. Nonparametric tests were performed on the behavioural categories and mortality rate and significance was evaluated by $\chi^{2}$ value and set at $P \leq 0.05$.

\section{Results and discussion}

\subsection{Growth performance}

The data relating to the productive performance are shown in Table 3. All parameters (LW, FI, FCR, mortality) were affected by genotype $(P<0.05)$ and housing system $(P<0.005)$. Furthermore, the interaction housing system $\mathrm{x}$ genotype effects resulted significant $(P<$ $0.005)$.

As expected, the final LW, the FI and the FCR differed between genotypes with higher values for Ross 308 compared to LBs and their crossbred, in both conventional and freerange systems. Mortality rate showed interesting results. Ross mortality was significantly $(P$ $<0.005)$ higher in both housing systems with higher percentage in the free-range system compared to the conventional.

As far as Ross growth performance is concerned, the comparison between the two rearing systems shows how this HPS performs less in a free-range system. On the other hand, all LBs and $\mathrm{F} 1$ crossed birds considered performed better in free-range rearing systems.

Previous research $[33,34]$ showed that the strong genetic selection for meat yield of HPS, provide increasingly better growth performances and yields, but the obvious consequence is that these animals are more susceptible to environmental variations, reducing their adaptability to uncontrolled environments and making them inappropriate for any type of farming other than the conventional intensive one.

Table 3. Productive performance of each genotype in the two rearing systems

\begin{tabular}{|c|c|c|c|c|c|}
\hline Housing System & Genotype & $\begin{array}{l}\mathrm{LW} \\
(\mathrm{g}) \\
\end{array}$ & $\begin{array}{c}\text { FI } \\
(\mathrm{g} / \mathrm{d})\end{array}$ & FCR & $\begin{array}{c}\text { Mortality } \\
(\%)\end{array}$ \\
\hline \multirow{5}{*}{ Conventional } & $\mathrm{BP}$ & 1.500 & 85.11 & 4.59 & 1.2 \\
\hline & $\mathrm{BPxS}$ & 1.982 & 87.81 & 3.55 & 0.9 \\
\hline & RM & 1.588 & 81.61 & 4.13 & 1.4 \\
\hline & $\mathrm{RMxS}$ & 2.035 & 90.61 & 3.58 & 1.7 \\
\hline & Ross & 4.920 & 175.15 & 2.88 & 3.0 \\
\hline \multirow{5}{*}{ Free-range } & $\mathrm{BP}$ & 1.660 & 99.88 & 4.87 & 0.0 \\
\hline & $\mathrm{BPxS}$ & 2.052 & 102.38 & 4.04 & 0.0 \\
\hline & RM & 1.620 & 96.58 & 4.89 & 0.5 \\
\hline & $\mathrm{RMxS}$ & 2.380 & 105.39 & 3.58 & 0.0 \\
\hline & Ross & 4.185 & 191.55 & 3.69 & 3.9 \\
\hline \multicolumn{6}{|c|}{ Significance of effect } \\
\hline \multicolumn{2}{|l|}{ Housing } & ** & ** & ** & ** \\
\hline \multicolumn{2}{|l|}{ Genotype } & $*$ & $*$ & $*$ & $*$ \\
\hline \multicolumn{2}{|l|}{$\mathrm{H} \times \mathrm{G}$} & ** & ** & $* *$ & ** \\
\hline
\end{tabular}

${ }^{*}=\mathrm{P}<0.05 .^{* *}=\mathrm{P}<0.005^{* * *} . \mathrm{H}=$ housing system. $\mathrm{G}=$ genotype. $\mathrm{H} \times \mathrm{G}$ interaction. 
LBs, on the other hand, showed lower to none mortality rate in the free-range system, thus implying a better resilience of these animals and a more appropriate fit to this rearing system [35].

Causes of Ross mortality were related to fast growth and were mainly Sudden Death Syndrome (SDS) $(65 \%)$ and ascites (35\%) in conventional system, whereas for free-range mainly ascites $(80 \%)$. This lower incidence of SDS in the free-range system $(20 \%)$ was probably a consequence of the lowering of the growing rhythm due to the housing system (diet + uncontrolled environmental condition + lower density + higher locomotor activity) $[36,37]$.

Another interesting finding is that for the $\mathrm{F} 1$ crossbred (BPxS, RMxS) showed adequate performance in both environments, conjugating the strength and resistance of LBs with higher yields [38, 39]. The FI was lower in free-range housing system of LBs and their crossbred, probably due to the grass ingestion (as confirmed by behavioural analysis), among other things, positively conditioning the other production parameters such as LW, FCR and mortality, too. These results are confirmed also by previous research [40] in different genotypes (mainly HPS vs LBs) reared in organic system, where grass ingestion improved LBs health and welfare and products (meat and egg) quality.

The crossing of pure breeds with HPS [41] had a positive impact in LW of LBs genotypes, in both rearing systems, this result can be deeply analysed observing the LW Gompertz curves (fig. 2, 3). In fact, as previous studies confirm [42], BP has a faster growing rate in the first part of its life cycle (4-7 weeks), while RM in the second part of its life cycle (8-13 weeks). In the Gompertz model, parameter b3, which was related to the shape of the growth curve, showed positive correlation with BW and in RM free-range birds showed the highest value $\left(11.75, \mathrm{R}^{2}=0.99\right)$. Crossing LBs with HPS bird line, improved RM growth in the first phase while in the second sustained the BP growth allowing the curves of BPxS with RMxS to be comparable since week 1 in both systems (b3 = 9.61 and 10 for BPxS and RMxs, respectively). The relative growth rate $\mathrm{b} 2$, related to the slope of the curve, was the highest in conventional Ross $\left(0.27, \mathrm{R}^{2}=0.98\right)$. Accordingly, the higher $\mathrm{b} 2$ value corresponded to a shorter time to reach maturity.

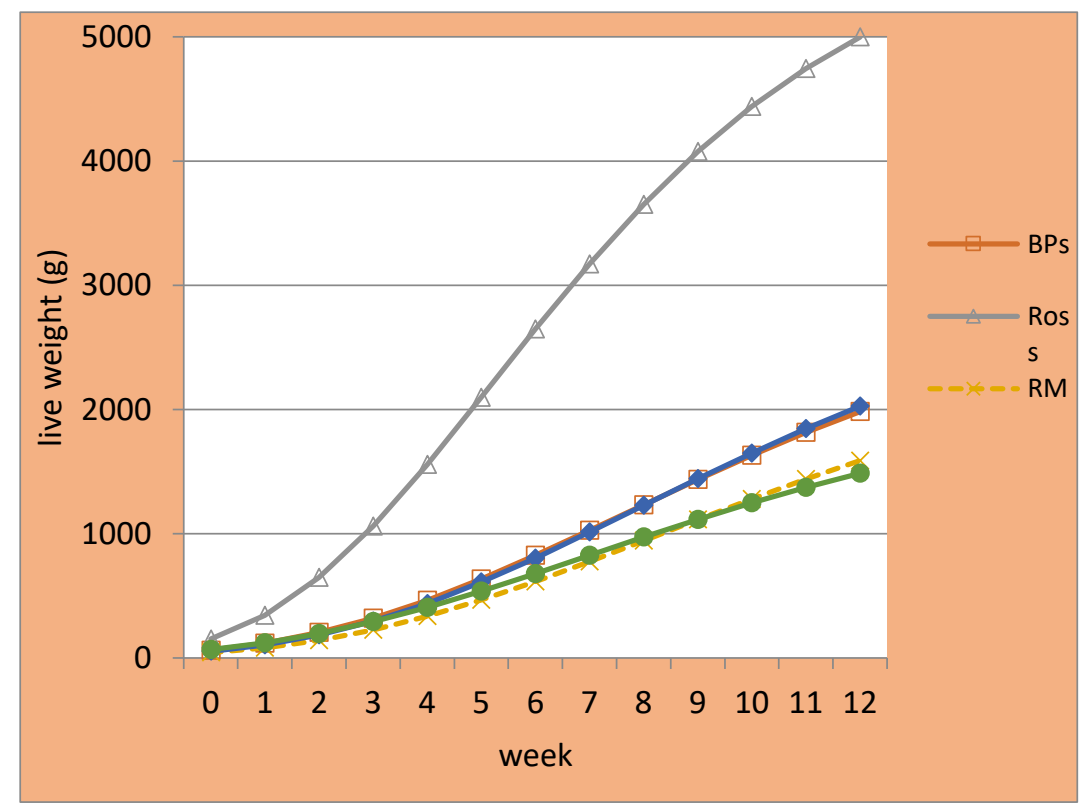

Fig. 1. Gompertz distribution of LW from 0 to 12 weeks of conventional system. 


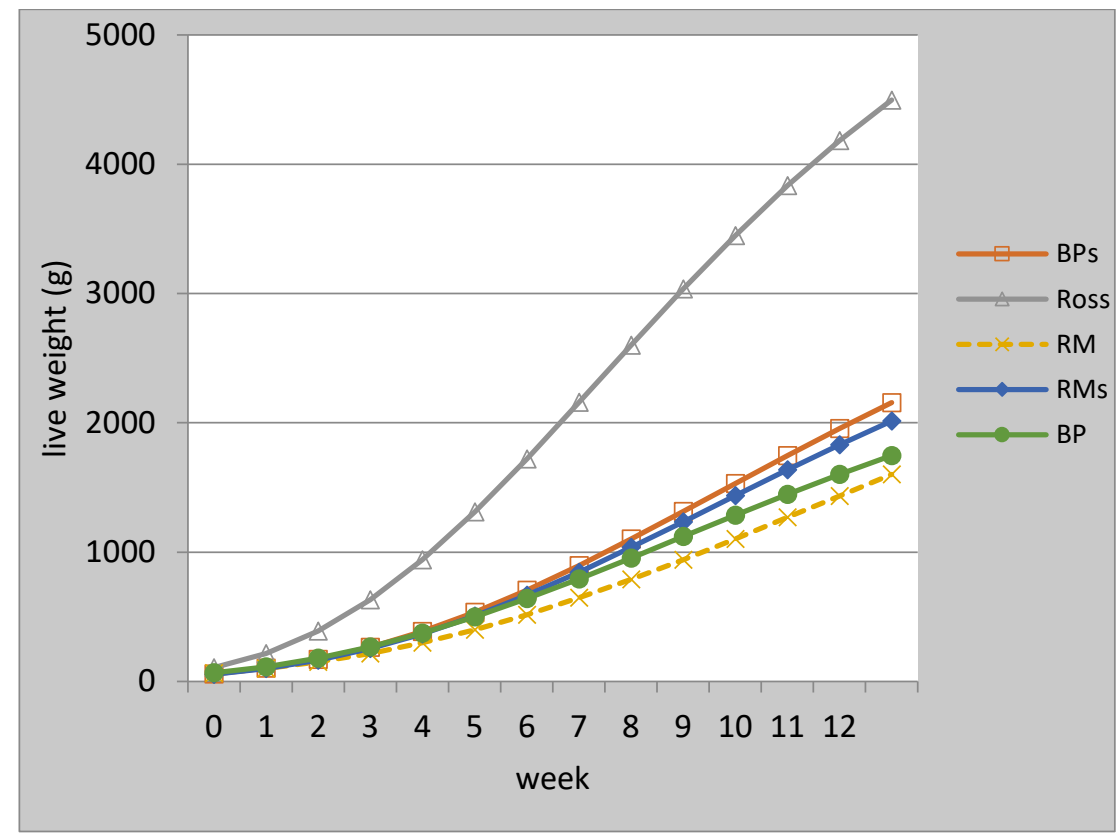

Fig. 2. Gompertz distribution of LW from 0 to 12 weeks in free-range system.

\subsection{Behavioural analysis}

Analysis of animal behaviours in farming is important from a multifactorial point of view; results obtained from more traditional observed point (i.e. performance) in poultry farming, can be put in correlation and explained observing the behaviour that animals show [43].

The results obtained are present in Table 4; macro-categories like feeding, locomotor, resting, and comfort showed strong significance $(P<0.005)$ for housing system and genotype, the interaction between housing and genotype was significant $(P<0.05)$ for feeding and rest and showed a strong significance $(P<0.005)$ only for locomotor activities.

To deeply understand differences founds in birds feeding activities, we must analyse the behavioural patterns that constitute this macro-category. In fact, feeding was constituted by scratching, feeding from feeders and drinkers, and grass/object pecking. In free-range birds, feeding was mainly constituted by grass pecking in all genotypes, while in conventional, this behaviour was not allowed, and it was substituted by pecking objects. Regarding feeding from feeders, the conventional birds performed the greater percentage (data not shown). Respect to genotype Ross showed in both systems the highest percentage of feeding from feeders according to due to genetic selection [44].

As expected, in both rearing systems, Ross showed the lowest locomotor activities; particularly interesting is that in both housing systems there was no significant difference, these animals even if given the opportunity of an outside area where they could move freely, spent, like in the conventional housing system, a lot of their daily time resting and feeding at feeders. On the contrary free-range LBs and their crossbred took advantage of the outdoor area, showing more locomotor and less resting feeding at feeders activities compared to conventional farmed animals, these results are confirming previous studies [40] showing how strong genetic selections have impacted the life of this animals.

Since active behaviours (i.e., running and walking) represent an energy cost for the animal, it is plausible that the strong genetic selection carried out to improve productive performance modifies the behaviour of these animals, forcing them to direct as much energy 
as possible to growth, by limiting some behaviours wasteful in terms of energy [45]. This confirms what has been observed, in both housing systems, regarding Ross, which spent most of their energy on muscle growth, while in LBs a greater percentage of available resources have been used for movement, food search and performing behaviour typical of the chicken ethogram. Consequently, it could be possible that genetic selection for productive traits (i.e. muscle growth, breast yield) indirectly produce animals with a reduced kinetic attitude [46].

Table 4. Behavioural macro-categories of birds in the two rearing systems

\begin{tabular}{|l|l|c|c|c|c|c|c|}
\hline Housing System & Genotype & Feeding & Locomotor & Social & Resting & Comfort & Stretching \\
\hline \multirow{5}{*}{ Conventional } & Bp & 22.56 & 23.48 & 4.03 & 41.65 & 4.39 & 4.03 \\
\cline { 2 - 9 } & Rm & 17.59 & 30.80 & 4.43 & 38.65 & 4.28 & 4.24 \\
\cline { 2 - 9 } & Bp X S & 21.63 & 25.44 & 3.71 & 41.90 & 3.08 & 4.23 \\
\cline { 2 - 9 } & Rm X S & 17.40 & 20.91 & 2.97 & 50.18 & 5.20 & 3.35 \\
\cline { 2 - 9 } & Ross & 14.99 & 12.32 & 0.00 & 59.21 & 2.92 & 11.28 \\
\hline \multirow{5}{*}{ Free-Range } & Bp & 34.09 & 41.70 & 5.98 & 13.45 & 3.50 & 1.52 \\
\cline { 2 - 9 } & Rm & 32.20 & 41.85 & 3.85 & 17.37 & 3.07 & 1.65 \\
\cline { 2 - 9 } & Bp X S & 34.07 & 41.05 & 5.44 & 16.94 & 1.35 & 1.14 \\
\cline { 2 - 9 } & Rm X S & 40.22 & 38.75 & 5.73 & 11.45 & 3.23 & 0.75 \\
\cline { 2 - 9 } & Ross & 21.25 & 13.39 & 0.18 & 53.82 & 5.30 & 7.45 \\
\hline \multirow{5}{*}{$P$ Value } & Housing & $* *$ & $* *$ & - & $* *$ & $* *$ & $*$ \\
\cline { 2 - 9 } & Genotype & $* *$ & $* *$ & - & $* *$ & $* *$ & $*$ \\
\cline { 2 - 9 } & H X G & $*$ & $* *$ & - & $*$ & - & - \\
\hline
\end{tabular}

$*=P<0.05 . * *=P<0.005 . \mathrm{H}=$ housing system. $\mathrm{G}=$ genotype. $\mathrm{H} \times \mathrm{G}$ interaction.

Comfort behaviours were mainly constituted by self-preening and sand bath and were mostly performed in conventional system by LBs and their crossbred, while in free range housing system by Ross birds. We could hypothesize that more active birds like LBs and their crossbred, when reared in confined environment, increase the time spent in performing allowed behaviours, this hypothesis was confirmed by the findings of the same genotypes in free-range lowered the frequencies of comfort behaviour, being free to perform their natural ethogram.

Ross when compared to LBs and crossbred performed more stretching. Leg and wing stretching intended as extending these parts from the body could be performed in order to relieve pain or discomfort due to the posture in meat type birds [47]. On the contrary, other studies have also reported that a lack of stretching could be a sign of compromised bird health [48]. Accordingly, LBs and crossbred performed a lower frequency of stretching, this could be explained by the fact that they were engaged performing other behaviors of their ethogram. Previous studies conducted in laying hens have showed that stretching could be mainly linked to the productive factors of farming, such as the type of soil confirming that HPS are less tolerant, if environmental conditions are not ideal $[49,50]$.

\section{Conclusion}

Our results clearly demonstrate that Ross birds increase their mortality in free-range system, whereas in the same system, LBs and their crossbred increased their productive performance with the lowest mortality and then better welfare. 
These findings clearly show how HPS such as Ross 308 can give unparalleled meat yields in conventional system, with high quality feed, controlled environment, and short life cycle. If these conditions are not guaranteed, such as in free-range, Ross genotype birds did not take advantage of space and pasture allowance and did not modify their behavioural patterns as opposed to LBs and their crossbred.

We can then state that, LBs and their crossbred can better adapt to alternative farming systems, showing resilience of local poultry production to environmental changes. Moreover, the crossbreeding of LBs with a more productive breed could have a great effect in improving productive performance without impairing animal behaviour and welfare, increasing the economic income for local farmers.

This is useful knowledge both for less developed and developed countries where is important to develop low input farming system to sustain local communities and economies, and to meet consumers demands of animal product with higher welfare and ethical value being.

We can then conclude that less productive chicken breeds can represent a feasible alternative in the appropriate rearing system.

Further experimental trial regarding this argument could be performed as very little previous bibliography is present on this topic, it could be particularly interesting to analyse in more details the increase in performance in relation to strength and resilience of population of LBs crossed with higher productive strains.

This study was supported by the Italian Ministry of Research and University funding project PRIN: "USE OF LOCAL CHICKEN BREEDS IN ALTERNATIVE PRODUCTION CHAIN: WELFARE, QUALITY AND SUSTAINABILITY" (Prot. 2017S229WC).

\section{References}

1. FAO, The Future of Food and Agriculture: Trends and Challenges, 4 (2017)

2. M. De Vries, I. J. M. De Boer, Livest. Sci., 128, 1-11 (2010)

3. M. J. Zuidhof, B. L. Schneider, V. L. Carney, D. R. Korver, F. E. Robinson, Poult. Sci. 93, 2970-2982 (2014)

4. R. Relić, E. Sossidou, A. Dedousi, L. Perić, I. Božičković, M. Đukić-Stojčić, Ankara Univ. Vet. Fak. Derg. 66, 423-428 (2019)

5. M. Petracci, F. Soglia, C. Berri, pp. 51-75, Woodhead Publishing (2017)

6. A. F. Soleimani, I. Zulkifli, A. R. Omar, A. R. Raha, Poult. Sci., 90, 1435-1440 (2011)

7. W. M. Muir, H.-W. Cheng, C. Croney, Front. Genet. 5, 407 (2014)

8. P. Parrot, K. Walley, in Poultry Quality Evaluation, pp. 313-334 (2017)

9. A. C. Mancinelli, M. Guarino Amato, D. Meo Zilio, A. Dal Bosco, S. Mattioli, C. Castellini, J. Dairy Vet. Sci. 4, 555644 (2017)

10. A. Franzoni, M. Gariglio, A. Castillo, D. Soglia, S. Sartore, A. Buccioni, F. Mannelli, M. Cassandro, F. Cendron, C. Castellini, A.C. Mancinelli, S. Cerolini, A. Sayed, N. Iaffaldano, M. Di Iorio, M. Marzoni, S. Salvucci, A. Schiavone, Animals 11, 629, (2021)

11. H. Nurcahya, S. Darwati, I. J. Tambunan, J. Trop. Biodiv. 1, 63-73 (2020)

12. I. Hoffmann, Worlds. Poult. Sci. J. 61, 57-70 (2005)

13. L. Baldinger and R. Bussemas, Org. Agric. 11, 489-498 (2021)

14. P. Rosa, B. Ávila, I. Angelo, R. Chesini, T. Fernandes, J. Camacho, M. Bugoni, V. Roll, M. Gularte, Br. Poult. Sci. 62, 387-395 (2021)

15. F. Kaygisiz, B. A. Bolat, and D. Bulut, Rev. Bras. Cienc. Avic. 21, eRBCA-20191060 (2019) 
16. FAO, "The Second Reports of the State of the World's Animal Genetic Resources for Food and Agriculture" (2015)

17. A. Castillo, M. Gariglio, A. Franzoni, D. Soglia, S. Sartore, A. Buccioni, F. Mannelli, M. Cassandro, F. Cendron, C. Castellini, Alice Cartoni Mancinelli, N. Iaffaldano, M. D. Iorio, M. Marzoni, S. Salvucci, S. Cerolini, L. Zaniboni, A. Schiavone, Animals 11, $490(2021)$

18. E. Commission, https://europa.eu/european-union/about-eu/funding-grants_en.

19. Veneto Agricoltura, https://www.venetoagricoltura.org.

20. D. Soglia, S. Sartore, S. Maione, A. Schiavone, S. Dabbou, J. Nery, L. Zaniboni, S. Marelli, P. Sacchi, R. Rasero, Animals 10, 969 (2020)

21. https://www.venetoagricoltura.org/

22. D. Soglia S. Sartore, S. Maione, A. Schiavone, S. Dabbou, J. Nery, L. Zaniboni, S. Marelli, P. Sacchi, R. Rasero, Poult. Sci. 96, 2552-2561 (2017)

23. V. Ferrante, C. Mugnai, L. Ferrari, S. P. Marelli, E. Spagnoli, S. Lolli, Ital. J. Anim. Sci. 15, 303-309 (2016)

24. M. G. Strillacci, M. C. Cozzi, E. Gorla, F. Mosca, F. Schiavini, S. I. Román-Ponce, F. J. Ruiz López, A. Schiavone, M. Marzoni, S. Cerolini, A. Bagnato, Animal 11, $737-$ 745 (2017)

25. http://www.gallinabianca.it

26. Aviagen, "Ross-Broiler Management Handbook 2018," p. 5 (2018)

27. European Union, "Council Directive 834/2007 on organic production and labelling of organic products" (2007)

28. Feedipedia (2021)

29. Arlington, "AOAC. International Official methods of analysis of AOAC,"

30. THE Commission, OF The, and E. Communities, "L 257/14," Communities, no. January, pp. 14-28 (1999)

31. M. Bateson, P. Martin, Behav. Res. Ther. 32, 898 (1994)

32. StataCorp, "Stata Statistical Software, Release 9.0. College Station, TX 2005"

33. S. Mueller, M. Kreuzer, M. Siegrist, K. Mannale, R. E. Messikommer, I. D. M. Gangnat, Poult. Sci. 97, 3325-3336 (2018)

34. K. Wang, S. Shi, T. Dou, H. Sun, Poult. Sci. 88, 2219-2223 (2009)

35. A. Dal Bosco, S. Mattioli, A. Cartoni Mancinelli, E. Cotozzolo, and C. Castellini, Animals, 11, 1281 (2021)

36. M. Azizian, A. A. Saki, J. Hell. Vet. Med. Soc. 71, 2087 (2020)

37. K. M. Hartcher, H. K. Lum, Worlds. Poult. Sci. J. 76, 154-167 (2020)

38. F. S. Guni, S. H. Mbaga, A. M. Katule, and E. H. Goromela, Trop. Anim. Health Prod. 53, 53-59 (2021)

39. Y. D. Sanka, S. H. Mbaga, S. K. Mutayoba, A. M. Katule, and S. H. Goromela, Trop. Anim. Health Prod. 52, 3315-3322 (2020)

40. C. Castellini, C. Mugnai, L. Moscati, S. Mattioli, M. Guarino Amato, A. Mancinelli, A. Dal Bosco, Ital. J. Anim. Sci. 15, 37-46 (2016)

41. https://www.hendrix-genetics.com/en/

42. C. Castellini, A. Dal Bosco, C. Mugnai, and M. Bernardini, Ital. J. Anim. Sci. 1, $291-$ $300(2002)$

43. S. Bergmann, A. Schwarzer, K. Wilutzky, H. Louton, J. Bachmeier, P. Schmidt, M. Erhard, E. Rauch, J. Vet. Behav. Clin. Appl. Res. 19, 90-101 (2017)

44. C. W. Tallentire, I. Leinonen, and I. Kyriazakis, Sci. Rep. 8, 1168 (2018)

45. E. H. van der Waaij, J. Anim. Sci. 82, 973-981 (2004)

46. A. Cartoni Mancinelli, S. Mattioli, A. Dal Bosco, A. Aliberti, M.G. Amato, C. Castellini, Animals, 10, 550 (2020)

47. W. Bessei, Worlds. Poult. Sci. J. 62, 455-466 (2006) 
48. G. Li, Y. Zhao, Z. Porter, J. L. Purswell, Animal 15, 36-38 (2021)

49. J. Carol Petherick, E. Seawright, D. Waddington, I. J. H. Duncan, L. B. Murphy, Anim. Behav. 49, 1521-1530 (1995)

50. B. L. Nielsen, Br. Poult. Sci., 45, 306-315 (2004) 